\title{
Photosensitizer and peptide-conjugated PAMAM dendrimer for targeted in vivo photodynamic therapy
}

\author{
Amreddy Narsireddy' \\ Kurra Vijayashree ${ }^{2}$ \\ Mahesh G Adimoolam' \\ Sunkara V Manorama' \\ Nalam M Rao ${ }^{2}$ \\ 'CSIR - Indian Institute of Chemical \\ Technology, ${ }^{2}$ CSIR - Centre for \\ Cellular and Molecular Biology, \\ Hyderabad, India
}

This article was published in the following Dove Press journal:

International Journal of Nanomedicine

3 November 2015

Number of times this article has been viewed

\begin{abstract}
Challenges in photodynamic therapy (PDT) include development of efficient near infrared-sensitive photosensitizers (5,10,15,20-tetrakis(4-hydroxyphenyl)-21 $\mathrm{H}, 23 \mathrm{H}$-porphine [PS]) and targeted delivery of PS to the tumor tissue. In this study, a dual functional dendrimer was synthesized for targeted PDT. For targeting, a poly(amidoamine) dendrimer (G4) was conjugated with a PS and a nitrilotriacetic acid (NTA) group. A peptide specific to human epidermal growth factor 2 was expressed in Escherichia coli with a His-tag and was specifically bound to the NTA group on the dendrimer. Reaction conditions were optimized to result in dendrimers with PS and the NTA at a fractional occupancy of $50 \%$ and $15 \%$, respectively. The dendrimers were characterized by nuclear magnetic resonance, matrix-assisted laser desorption/ionization, absorbance, and fluorescence spectroscopy. Using PS fluorescence, cell uptake of these particles was confirmed by confocal microscopy and fluorescence-activated cell sorting. PS-dendrimers are more efficient than free PS in PDT-mediated cell death assays in HER2 positive cells, SKOV-3. Similar effects were absent in HER2 negative cell line, MCF-7. Compared to free PS, the PS-dendrimers have shown significant tumor suppression in a xenograft animal tumor model. Conjugation of a PS with dendrimers and with a targeting agent has enhanced photodynamic therapeutic effects of the PS.
\end{abstract}

Keywords: photodynamic therapy, dendrimers, nanoparticle, targeted delivery, Affibody, xenograft animal model

\section{Introduction}

Photodynamic therapy (PDT) is a nonsurgical and minimally invasive procedure that is rapidly developing as a preferred treatment modality for cancer as well as for some dermatological and ophthalmic diseases. ${ }^{1,2}$ PDT requires a photosensitizer, light, and oxygen to generate reactive oxygen radicals that oxidize biomolecules and cause cell death in the surrounding tissue. ${ }^{3,4}$ The main advantage of PDT over cancer chemotherapy is the capability to localize the treatment. By controlling light exposure to the tumor site, preferential cell death in the presence of 5,10,15,20tetrakis(4-hydroxyphenyl)-21H,23H-porphine (PS) in the targeted tissue could be achieved..$^{5-7}$ US Food and Drug Administration has approved two porphyrin-based photosensitizers, hematoporphyrin derivatives (Photofrin, Pinnacle Biologics, Chicago, IL, USA) and meta-tetra(hydroxyphenyl)chlorin (Foscan, Scotia Pharmaceuticals, Stirling, Scotland) for PDT. ${ }^{8}$ Photosensitizers have limited solubility in water and thus require a suitable pharmaceutical formulation for parenteral administration. Several PS formulations based on micelles, liposomes, polymeric and ceramicbased nanoparticles, prodrugs, dendrimers, etc have been successfully tested. ${ }^{4,9,10}$ 
Current efforts in improving PDT focus on strategies to increase the solubility of the PS to prevent self-quenching, design new PS molecules to absorb light in near-infra red region, and strategies that facilitate higher accumulation of PS in the diseased tissue. Targeted PDT is a specific effort to restrict the oxidative damage only to the disease tissue and reduce the damage to the surrounding tissue. Strategies in targeted PDT exploit the biochemical differences between the normal and deceased tissue to increase the accumulation of PS. ${ }^{11}$

Dendrimers are highly branched nanoscale macromolecules, possessing a large number of functional end groups. ${ }^{12,13}$ Uniform size of dendrimers enables reproducible pharmacokinetics and they are regarded as promising candidates for use in biomedical applications. ${ }^{12-14}$ In recent years, dendritic scaffolds have been explored for their use in biomedical applications, such as drug delivery, ${ }^{15}$ synthetic vaccination, ${ }^{16}$ magnetic resonance imaging, ${ }^{17}$ and tissue engineering. ${ }^{18}$ In PDT, PS-dendrimer conjugates are tested by three strategies. PS is entrapped in the voids of a dendrimer, ${ }^{19}$ or PS is covalently attached to the dendrimers. ${ }^{20}$ In the third strategy, PS is used as a scaffold to generate a dendrimer. ${ }^{21}$ 5-Aminolevulinic acid (5-ALA)-conjugated dendrimers showed efficient PDT in cell lines. ${ }^{22}$ A number of studies have tested the PS-dendrimer complexes; however, very few studies have tested the formulations in in vivo tumor regression studies. ${ }^{23,24}$

Commercially available fourth generation poly (amidoamine) (PAMAM) dendrimers are used in this study. PAMAM $_{\text {IV }}$ dendrimer has 64 amine peripheral groups on its surface and these amine groups were partially converted into carboxylate using succinic acid for attaching PS and Affibody, a targeting peptide via a nitrolotriacetic acid group. Drug nanoformulations have been targeted to tumors by attaching small molecular ligands such as folic acid, sugars, etc or with large molecules such as antibodies, ferritin, etc. ${ }^{25}$ Many tumors overexpress specific surface proteins and receptors that could be used to direct a formulation to a tumor. Human epidermal growth factor receptors (EGFR) are type-1 transmembrane receptor tyrosine kinases that are overexpressed in several cancers. ${ }^{26}$ HER2 receptor, a member of human EGFR, upon activation imparts proliferative properties to cells and was shown to be an important marker for breast cancer. ${ }^{27,28}$ In this study, an in vitro evolved peptide ligand for HER2 known as HER2 3-340 (Affibody) was used as a tumor-targeting peptide. ${ }^{29,30}$ The excellent binding property of this Affibody to HER2 was extensively used in several medical applications. ${ }^{31}$ We produced the Affibody by heterologous expression in Escherichia coli. His-tagged Affibody was bound to the dendrimer via a nitrolotriacetic acid group attached to the dendrimers. ${ }^{32}$ A scheme depicting the strategy followed in generating PS-dendrimer conjugates is presented in Figure 1.

\section{Experimental details}

\section{Materials}

G4 amine-terminated PAMAM dendrimers were purchased from Dendritech, Inc., Midland, MI, USA, $(10.0 \% \mathrm{w} / \mathrm{w}$ and $4.95 \% \mathrm{w} / \mathrm{w}$ in $\mathrm{MeOH}$, respectively). Dichloro methane (DCM), dimethyl formamide (DMF), 4-dimethylaminopyridine (DMAP), PS, dimethyl sulfoxide (DMSO), 1-ethyl-3-(3-dimethylaminopropyl)carbodiimide (EDC), $N$-hydroxysuccinamide (NHS), succinic acid (SA), $N_{\alpha}, N_{\alpha}$-bis(carboxymethyl)-L-lysine hydrate, 2,5-dihydroxybenzoic acid, glutaraldehyde, nickel chloride $\left(\mathrm{NiCl}_{2} \cdot 6 \mathrm{H}_{2} \mathrm{O}\right)$, 1,3-diphenylisobenzofuran (DPBF), dialysis tubing, and Dulbecco's Modified Eagle's Medium (DMEM) were purchased from Sigma-Aldrich, St Louis, MO, USA. Matrigel was procured from BD Biosciences, San Jose, CA, USA. All other reagents were of highest purity and purchased locally.

\section{Methods}

\section{Carboxyl functionalization of PAMAM- $\mathrm{NH}_{2}$} dendrimer

The amine groups of PAMAM were converted into carboxyl groups with SA. SA (70.9 mg, $0.620 \mathrm{mmol})$ and $93.5 \mathrm{mg}$ of EDC $(0.620 \mathrm{mmol})$ were added to a $10 \mathrm{~mL}$ of solvent (DMSO:DMF, 3:1 v/v) and stirred for 10 minutes. To this mixture, $69.2 \mathrm{mg}$ of NHS $(0.620 \mathrm{mmol})$ was added and stirred for 10 minutes followed by addition of $50 \mu \mathrm{L}$ of

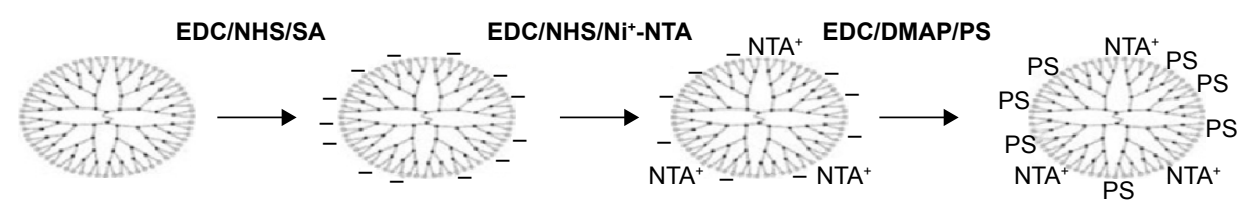

Figure I Scheme depicting the synthesis of the PS-functionalized G4 dendrimers.

Abbreviations: SA, succinic acid; EDC, I-ethyl-3-(3-dimethylaminopropyl)carbodiimide; NHS, N-hydroxysuccinamide; PS, 5, I0, I5,20-tetrakis (4-hydroxyphenyl)-2IH,23Hporphine; DMAP, 4-dimethylaminopyridine. 
PAMAM-NH 2 (0.301 mmol). This mixture was stirred overnight at room temperature under nitrogen gas environment. The crude product was dialyzed against DMSO with $10 \mathrm{kDa}$ molecular weight (MW) pore size dialysis membrane for 24 hours to remove the unreacted compounds.

\section{$N_{\alpha}, N_{\alpha}$-bis(carboxymethyl)-L-lysine hydrate attached to carboxyl functionalized PAMAM}

Carboxyl PAMAM (PAMAM-SA) was taken into a $10 \mathrm{~mL}$ DMSO and DMF (3:1 ratio) solvent mixture, and $46.72 \mathrm{mg}$ $(0.310 \mathrm{mmol})$ of EDC was added and stirred for 10 minutes, followed by addition of $34.6 \mathrm{mg}$ of NHS $(0.310 \mathrm{mmol})$ and again stirred for 10 minutes. Finally $10 \mathrm{mg}$ of modifiedNTA (0.040 mmol) was added and stirred overnight at room temperature under nitrogen atmosphere. At the end of this step, $10 \mathrm{mg}$ of nickel chloride $\left(\mathrm{NiCl}_{2} \cdot 6 \mathrm{H}_{2} \mathrm{O}\right)$ was added to this mixture and stirred for 2 hours. The crude product was purified by dialysis against DMSO with $10 \mathrm{kDa}$ pore size MW dialysis membrane for 24 hours to remove unreacted compounds.

\section{Photosensitizer, PS, attached to carboxyl functionalized PAMAM-NTA-Ni ${ }^{2+}$}

Carboxyl-PAMAM-NTA-Ni2+ ${ }^{2+}$ was dissolved in $20 \mathrm{~mL}$ of DMSO and DMF (3:1 ratio) solvent mixture, and $46.7 \mathrm{mg}$ of EDC (0.310 mmol) was added to it. After 10 minutes of stirring, $36.1 \mathrm{mg}$ of DMAP $(0.310 \mathrm{mmol})$ was added. This was followed by addition of $14 \mathrm{mg}$ of $(0.0212 \mathrm{mmol})$ photosensitizer and stirred for 48 hours at room temperature under nitrogen atmosphere. The above crude product was purified by dialysis initially against DMSO for 3 days and finally against PBS (phosphate-buffered saline) to remove DMSO.

\section{Characterization of the dendrimers}

The absorption and fluorescence spectra of PS were obtained using a GBC Varian UV-Vis (ultraviolet-visible) spectrometer (GBC Scientific Equipment, Braeside, Victoria, Australia) and Hitachi F7000 fluorescence spectrometer (Hitachi, Chiyoda, Tokyo, Japan), respectively. Concentrations of PS and dendrimers attached to PS were estimated by the absorption at $420 \mathrm{~nm}$. Proton nuclear magnetic resonance spectra ( ${ }^{1} \mathrm{H}$ NMR) (chemical shift in ppm with respect to deuterated DMSO [DMSO- $d_{6}$ ] set at 2.5) of the dendrimers were obtained on a $400 \mathrm{MHz}$ Avance-300 NMR spectrometer (Bruker AXS Inc., Madison, WI, USA), with samples dissolved in DMSO (DMSO- $d_{6}$ ). Transmission electron microscope (TEM; Philips Tecnai FEI F20, operating at $200 \mathrm{kV}$ ) was used to investigate the morphology and size of the dendrimer particles. Dendrimer samples placed on copper grids were paper blotted and air-dried before viewing in TEM. The samples were treated with uranyl acetate ( $1 \%$ aqueous solution) for negative staining.

The zeta potential values of dendrimers were recorded in phosphate buffered saline $(150 \mathrm{mM} \mathrm{NaCl}, 10 \mathrm{mM}$ sodium phosphate, buffer $\mathrm{pH} 7.2$ ) at $25^{\circ} \mathrm{C}$ using Malvern Zetasizer Nano S instrument (Malvern Instruments, Malvern, UK).

\section{Sample preparation for mass spectrometry}

Products at each step of conjugation were confirmed by electrospray ionization mass spectrometry (ESI-MS). The procedure is as follows: PAMAM dendrimer stock, carboxylPAMAM-Ni-NTA, PAMAM-(PS)-Ni-NTA (DPN) solution were diluted to a concentration of $\sim 10 \mathrm{pmol} / \mu \mathrm{L}$ in solutions of methanol, and mass spectra were acquired at a resolution of 100,000 at $m / z 400$. Mass spectrometry analysis was performed on a Thermo Finnigan LTQ Fourier transform mass spectrometer (Thermo Fisher Scientific, Bremen, Germany). Samples were injected by the use of an electrospray source (Advion Biosciences, Ithaca, NY, USA). Data acquisition and analysis were conducted using the Xcalibur 2.0 (Thermo Fisher Scientific) software and Promass software.

\section{Determination of singlet oxygen generation by DPBF assay}

Singlet oxygen generation by PS was determined by monitoring the photooxidation of DPBF. ${ }^{33} \mathrm{DPBF}$ is an acceptor because it absorbs in a region of dye transparency and rapidly scavenges singlet oxygen to give colourless products. Singlet oxygen generation studies were measured at low photosensitizer concentrations to minimize the possibility of singlet oxygen quenching by the photosensitizer. About $4 \mu \mathrm{L}$ of $8 \mathrm{mM}$ DPBF was added to $200 \mu \mathrm{L}$ of DMSO, with different concentrations of DPN particles and free PS. The samples were irradiated with 640-720 nm wavelength PDT instrument (PDT-1200 L, Waldmann, Villingen-Schwenningen, Germany) at a light dose of $20 \mathrm{~J} / \mathrm{cm}^{2}$. The optical density values of DPBF were recorded at $425 \mathrm{~nm}$ wavelength in a microplate reader (Multiskan Spectrum Elisa Reader, Thermo Fisher Scientific).

\section{Gel binding assay of DPN particles}

Affibody protein was purified as already described, without any modifications. ${ }^{34}$ Binding of His-tagged Affibody to DPN particles was investigated by sodium dodecyl sulfate-polyacrylamide gel electrophoresis (SDS-PAGE) gels. 
Different concentrations of DPN (0.375-15 nmol) were incubated with $5 \mu \mathrm{g}$ of Affibody for 1 hour. The samples were spun at $12,000 \mathrm{rpm}$ for 2 minutes, and $50 \mu \mathrm{L}$ of each sample supernatant (unbound protein) was loaded on a $15 \%$ SDS-PAGE gel and stained with Coomassie blue.

\section{Cell lines}

The human SK-OV-3 cell line overexpressing HER2 receptors (HER2+ cells) and MCF7 cell line (HER2- cells) were obtained from American Type Culture Collection (ATCC, Manassas, VA, USA) and cultured in DMEM supplemented with $10 \%$ fetal bovine serum and antibiotics. The cells were maintained at $37^{\circ} \mathrm{C}$ in a humidified $5 \% \mathrm{CO}_{2}$-containing atmosphere and subcultured biweekly to maintain subconfluent stocks.

\section{Cellular uptake of PAMAM dendrimer particles}

To study the cellular uptake of PAMAM dendrimer by SK-OV-3 cells, free PS, DPN, and ADPN (DPN with Affibody) were added at an equivalent PS concentration of $2 \mu \mathrm{M}-0.1$ million adherent cells on coverslips and incubated for 30 minutes. The cells were washed twice with PBS to remove unbound particles. For nucleus staining, cells were counterstained with Hoechst 33342 for 15 minutes. The cells were washed with PBS and fixed with a 4\% formaldehyde solution for 15 minutes. Fluorescence images of SK-OV-3 cells were visualized at $63 \times$ magnification using confocal laser scanning microscopy (Leica TCS SP5, Leica Microsystems, Wetzlar, Germany), with excitations set at 405 $\mathrm{nm}$ and emission set at $650 \mathrm{~nm}$ (PS) and $420 \mathrm{~nm}$ (Hoechst 33342). Acquisition conditions for all images or treatments were identical, and images were analyzed using LAS AF/ LSM 5 Image Examiner (Leica Microsystems).

\section{Light-induced cell death}

SK-OV-3 and MCF7 cells $\left(2 \times 10^{4}\right.$ cells/well) were seeded, each in two 96-well plates, and incubated overnight at $37^{\circ} \mathrm{C}$ in a humidified 5\% $\mathrm{CO}_{2}$ atmosphere. After 16 hours, the medium was replaced with fresh $100 \mu \mathrm{L}$ of complete DMEM medium (approximately at 80\% confluence). Cells were treated with various concentrations $(0.1-1 \mu \mathrm{M})$ of either free PS or PAMAM dendrimers, ie, DPN and ADPN. Free PS was added from a DMSO stock, and DMSO concentration was kept below 1\% (v/v). After 6 hours of incubation, the cells were rinsed twice with $200 \mu \mathrm{L}$ of PBS to remove unbound particles, and fresh $100 \mu \mathrm{L}$ of PBS was added to the cells. One of the two plates was irradiated using a PDT1200 at a light dose of $20 \mathrm{~J} / \mathrm{cm}^{2}$ (irradiance of $50 \mathrm{~mW} / \mathrm{cm}^{2}$ for
6 minutes 30 seconds). Light intensity of the PDT lamp was assessed by a light meter provided by the instrument supplier. After irradiation, cell medium was replaced with $200 \mu \mathrm{L}$ of complete DMEM medium and incubated for another 16 hours at $37^{\circ} \mathrm{C}$. The second plate, taken as dark control, was treated identically to experimental group except that this plate did not receive irradiation. After 16 hours incubation, the medium in both plates was replaced with $100 \mu \mathrm{L}$ of 3-(4,5-dimethylthiazol-2-yl)-2,5-diphenyltetrazolium bromide (MTT) solution ( $2 \mathrm{mg} / \mathrm{mL}$ in PBS buffer) and further incubated for 3 hours. At the end of the assay, MTT solution was removed and $100 \mu \mathrm{L}$ of mixture of DMSO and methanol $(1: 1 \mathrm{v} / \mathrm{v})$ was added to dissolve the blue formazan crystal produced by live cells. The plates were incubated for an additional 10 minutes on a shaker, and the absorbance was read at $540 \mathrm{~nm}$ in a microplate reader (Multiskan Spectrum Elisa Reader, Thermo Fisher Scientific). All treatments were performed in triplicate and the relative cell viability (\%) was

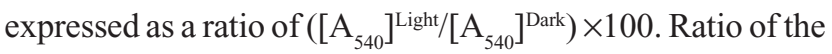
means was used to calculate the PDT effects. Each of these experiments was repeated thrice, and, in each experiment, the experimental error associated in triplicate measurements was less than $10 \%$.

\section{Mouse xenograft tumor models and PDT}

Foxn1 nude mice (6-8 weeks of age) of body weight of 18-20 g were maintained under cleanroom conditions in sterile filter top cages with corn cob bedding housed on high-efficiency particulate arrestance (HEPA)-filtered ventilated racks. Animals received sterile rodent chow and water ad libitum. Animal experiments were conducted in accordance with the guidelines of Institute Animal Ethics Committee (CPCSEA 20/1999). Two million SK-OV-3 cells were suspended in $100 \mu \mathrm{L}$ Matrigel and injected subcutaneously in the back right flank region of mice. Tumor growth was measured every day using vernier calipers, and the tumor volume was calculated by the formula (length $\times$ breadth $^{2} \times 0.5$ ). When tumor volume reached $\sim 100 \mathrm{~mm}^{3}$, the animals were randomized into eight groups of four animals per group. Each of the four treatments was performed on two groups, and one group was subjected to PDT and the other group was considered as dark control (no PDT). Following are the treatments: 1, PBS; 2, free PS; 3, DPN; and 4, ADPN. On the day of injections, ADPN was prepared by incubating $18 \mathrm{nmol}$ of DPN (based on PS absorption) with $5 \mu \mathrm{g}$ of Affibody in $0.6 \mathrm{~mL}$ of sterile PBS. All groups of mice were given $100 \mu \mathrm{L}$ of compound as intravenous injection via the tail vein. PS concentration in each set of groups was equivalent to $3.6 \mathrm{nmol}$. A day after the injection, 
the mice were anesthetized by intraperitonial injection of $0.1 \mathrm{~mL}$ of ketamine. Animals were masked except for the tumor and irradiated with PDT-1200 L (Waldmann) at a light dose of $120 \mathrm{~J} / \mathrm{cm}^{2}$ (irradiance of $200 \mathrm{~mW} / \mathrm{cm}^{2}$ for 10 minutes). Care was taken to maintain the temperature around the animals. Tumor volumes were monitored every day.

\section{Results}

\section{Proton nuclear magnetic resonance}

To confirm the progress in the synthesis of DPN, ${ }^{1} \mathrm{H}$ NMR spectra of the products at each step was recorded (Figure 2). Characteristic peaks of $\left(\mathrm{CH}_{2}-\right)$ of the commercially available G4-PAMAM-NH $\mathrm{N}_{2}$ appeared at 2.698-2.740 $\left({ }^{518} \mathrm{H}\right)$. After converting amine groups into carboxyl groups with succinic acid, the above characteristic peak was split and shifted to 2.531-2.477 $\left({ }^{197} \mathrm{H}\right)$ and $3.298-3.351\left({ }^{54} \mathrm{H}\right)$, and the new characteristic peak appeared at $2.775\left({ }^{3} \mathrm{H}\right)$, which belongs to $-\mathrm{CH}_{2}$ group of succinic acid. After conjugating with NTA, the characteristic peak shifted to $3.3(162 \mathrm{H})$ and $4.1(223 \mathrm{H})$, which belongs to $-\mathrm{CH}_{2}$ groups of PAMAM and lysine of the ligand. The $-\mathrm{CH}_{2}-\mathrm{COOH}$ of $\mathrm{CH}_{2}$ and carboxylate peaks appeared at $3.5\left({ }^{11.5} \mathrm{H}\right)$ and 11.4 (2) ppm, respectively. Subsequently conjugating with PS, the characteristic peaks appeared at $3.0\left({ }^{336} \mathrm{H}\right)$ and $3.3\left({ }^{294} \mathrm{H}\right)$. The phenyl proton NMR of PS appeared at 7.5 (5.8), 8.0 (4.3), and 8.9 (4) for $\mathrm{H}_{\mathrm{m}}, \mathrm{H}_{\mathrm{o}}$, and $\mathrm{H} \beta$, respectively.

\section{Absorption and fluorescence spectra}

The UV-Vis absorption spectrum of free PS and DPN composite has the same characteristics in DMSO solvent showing absorbance peak at $420 \mathrm{~nm}$, which is the Soret band
(Figure 3A), and the $\mathrm{Q}$ bands are located at 520, 560, 600, and $654 \mathrm{~nm}$ (Figure 3A). At the excitation wavelength of $420 \mathrm{~nm}$, PS and DPN produce strong fluorescence emission peaks at 655 and $720 \mathrm{~nm}$, respectively (Figure 3B). Upon attachment of the PS, the original spectral properties were retained suggesting that the conjugation did not cause any steric restriction on PS, and dendrimer environment did not affect the emission spectrum.

\section{ESI-MS analysis of the PAMAM dendrimers}

The expected mass of the commercial PAMAM dendrimer is $14,242.22 \mathrm{Da}$, and experimental mass analysis gave a $100 \%$ peak at 14,696 Da (Figure 4). After modification of peripheral amine groups of PAMAM dendrimer to carboxyl groups with SA, Ni-NTA conjugation resulted in a mass peak at 25,405 Da. Increase in mass of the dendrimer suggested attachment of 10 Ni-NTA groups per dendrimer molecule. Finally, PS was conjugated to carboxyl groups of carboxyl-PAMAMNi-NTA, and it gave $100 \%$ and $90 \%$, mass peaks appeared at 45,323 and 46,658 Da, which suggests a conjugation of 30-32 PS molecules per dendrimer.

\section{Zeta potential measurements}

At each step, PAMAM conjugations were monitored by measuring surface charge potential (Table 1). Commercial PAMAM dendrimer maintains near neutral charge $(-1.6 \mathrm{mV})$. Upon modification with carboxyl-PAMAM-Ni-NTA, it gives the $+25.6 \mathrm{mV}$ because of surface positive contribution from $\mathrm{Ni}^{2+}$ metal ions, which confirms the Ni-NTA groups on the surface of PAMAM. After conjugating PS molecules, the
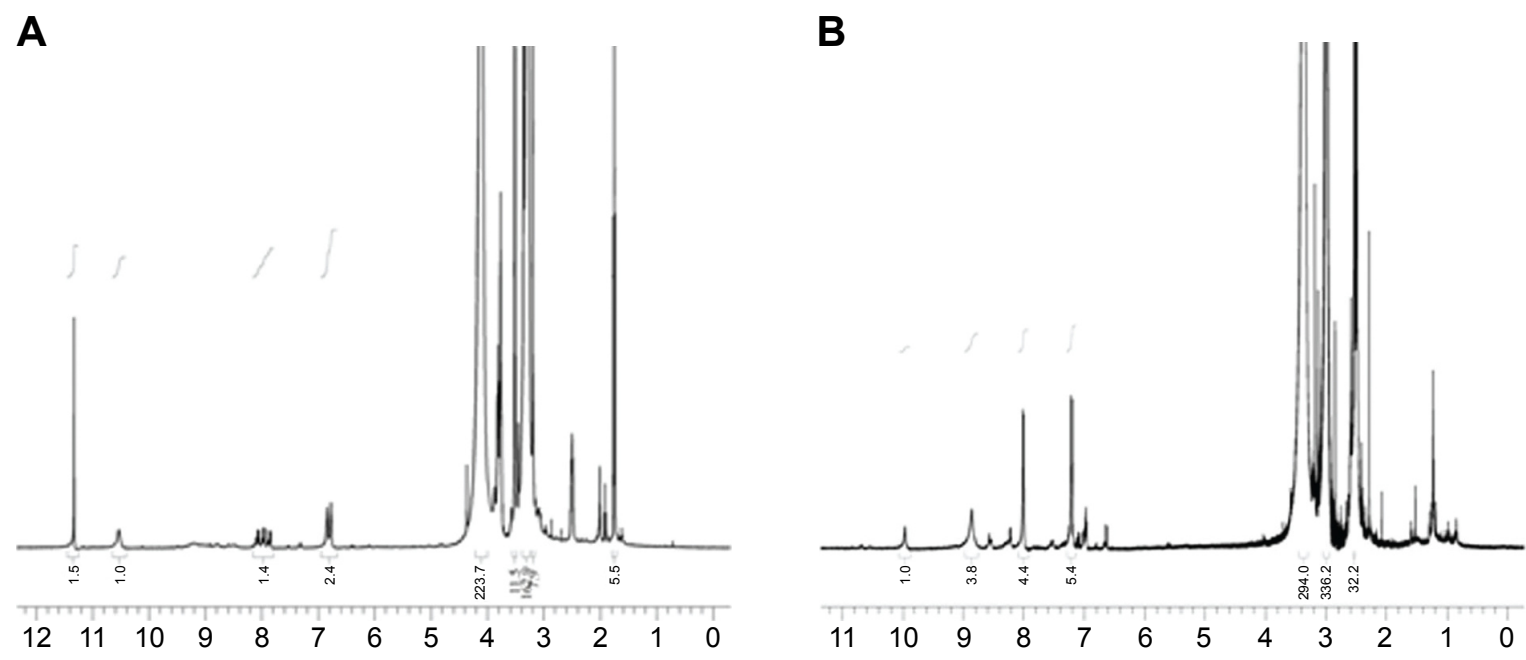

Figure 2 'H NMR spectra of (A) carboxyl-PAMAM-Ni-NTA and (B) PAMAM-NI-NTA-PS.

Abbreviations: 'H NMR, proton nuclear magnetic resonance; PAMAM, poly(amidoamine); PS, 5, I0,I5,20-tetrakis (4-hydroxyphenyl)-2IH,23H-porphine. 

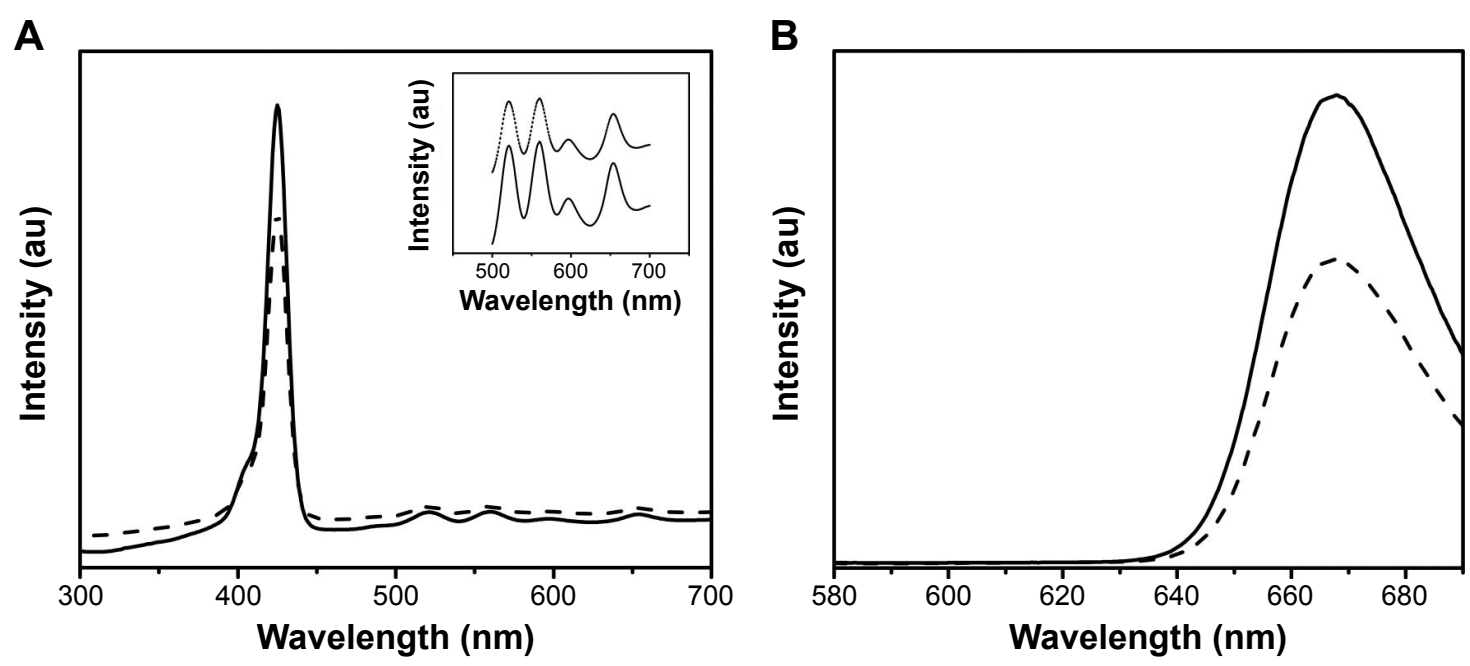

Figure 3 UV-visible (A) and fluorescence spectra (B) of free PS (continuous line) and DPN (hatched line).

Notes: Insert in (A) shows an enlarged absorption spectra of PS between 500 and $700 \mathrm{~nm}$. No spectral shift was observed upon conjugating PS to dendrimers.

Abbreviations: UV, ultraviolet; PS, 5,10,15,20-tetrakis (4-hydroxyphenyl)-2IH,23H-porphine; PAMAM, poly(amidoamine); DPN, PAMAM-(PS)-Ni-NTA; DPBF, I,3diphenylisobenzofuran.
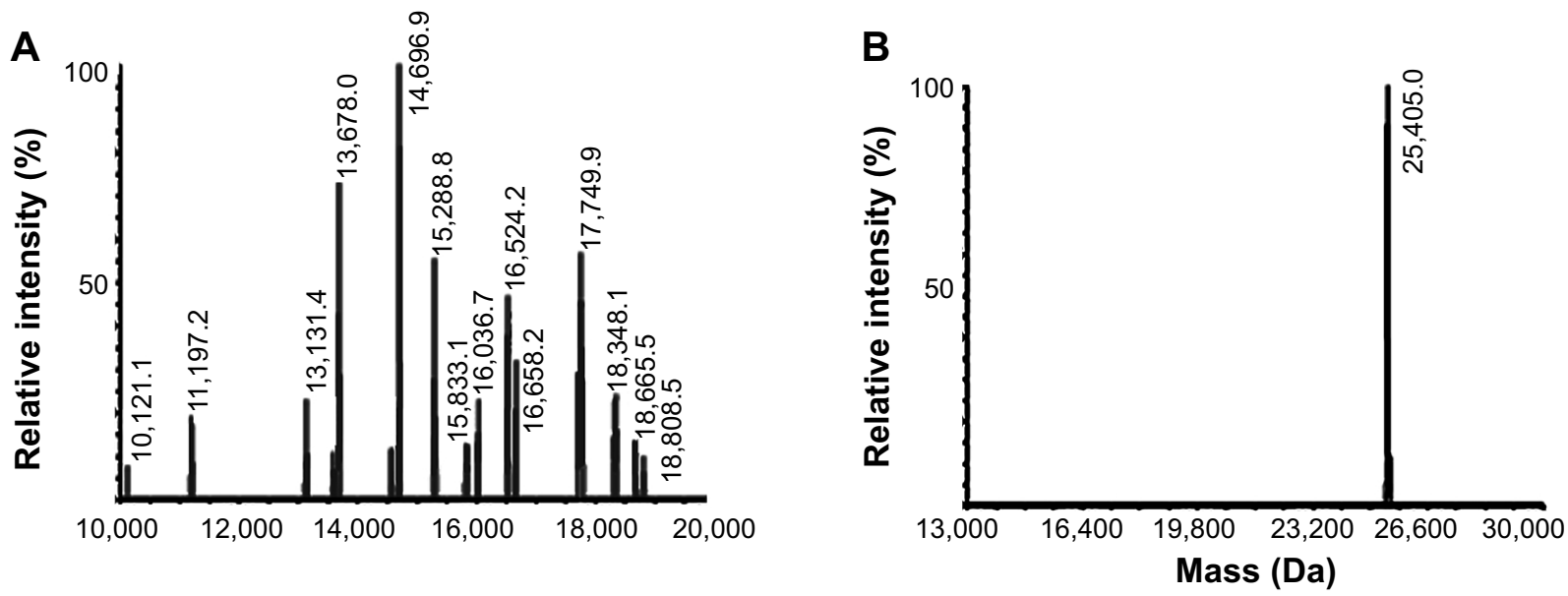

C

D
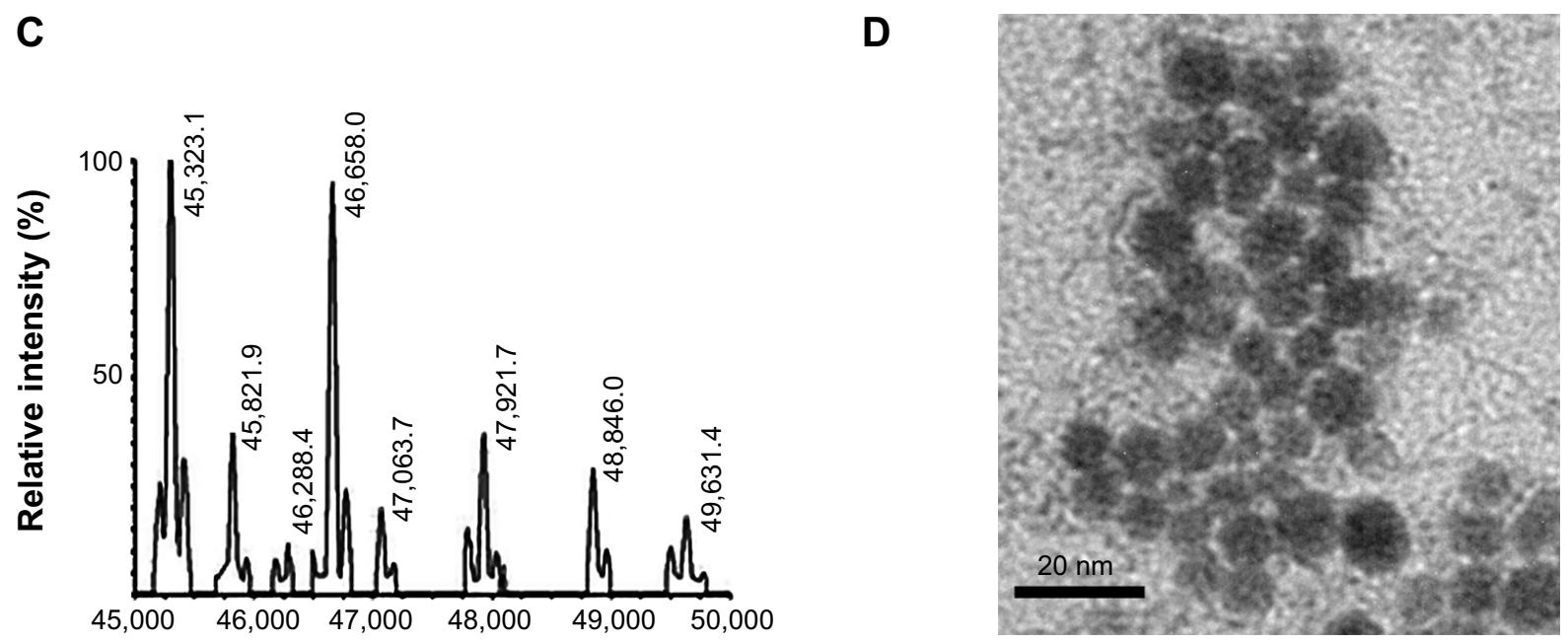

Figure 4 ESI-MS spectra of PAMAM (A), carboxyl-PAMAM-Ni-NTA, (B) and PAMAM-Ni-NTA-PS (C). (D) TEM image of Affibody attached dendrimers (ADPN). Note: Size of the bar in (D) is $20 \mathrm{~nm}$.

Abbreviations: ESI-MS, electrospray ionization mass spectrometry; PAMAM, poly(amidoamine); PS, 5,I0,I5,20-tetrakis (4-hydroxyphenyl)-2IH,23H-porphine; TEM, transmission electron microscope; DPN, PAMAM-(PS)-Ni-NTA; ADPN, DPN with affinity. 
Table I Zeta potential of the dendrimer and its derivatives

\begin{tabular}{ll}
\hline Samples & Zeta potential $(\mathbf{m V})$ \\
\hline PAMAM & -1.6 \\
PAMAM-Ni-NTA & +25.6 \\
PAMAM-Ni-NTA-PS & +2.5 \\
\hline
\end{tabular}

Abbreviations: PAMAM, poly(amidoamine); PS, 5, I0,15,20-tetrakis (4-hydroxyphenyl)-2IH,23H-porphine; DPN, PAMAM-(PS)-Ni-NTA; ADPN, DPN with affinity.

positive surface charge decreased to $+2.5 \mathrm{mV}$ due to the negative charge contribution of PS molecules.

DPN particles were imaged using TEM. The image in Figure 4D indicates an approximate size of $10 \mathrm{~nm}$ for DPN particles. G4 PAMAM dendrimers were estimated to have a diameter of $4.5 \mathrm{~nm} .{ }^{35}$ With the addition of PS and Ni-NTA group, the size of dendrimers has increased and resulted in uniformly spherical particles. Addition of acetylated glutamyl residues to G4 PAMAM dendrimers have shown a size of $7.5 \mathrm{~nm} .{ }^{36}$ An increase in dendrimer size to $10 \mathrm{~nm}$ may be expected upon conjugation of nearly $65 \%$ of the surface amine groups with PS and Ni-NTA groups. ADPN particles in similar conditions showed aggregates of $\sim 100-200 \mathrm{~nm}$ size (Figure S1).

\section{Singlet oxygen generation studies with DPBF}

Singlet oxygen generation by free PS and DPN particles was monitored by the extent of oxidative quenching of DPBF. Amount of PS present in the DPN was estimated by comparing its fluorescence with the standard curve generated on the basis of the fluorescence of known amount of PS. Different amounts of PS and DPN were mixed with DPBF and the samples were irradiated. As shown in Figure 5, DPBF absorbance, shown as difference between light exposed and unexposed treatment, increases with increasing amount of PS. ADPN also showed similar marginal improvement in $(\sim 20 \%)$ reactive oxygen species production compared to free PS. Care was taken to subtract the contributions of PS to the absorbance. At a given concentration of PS, DPBF quenching was more efficient in DPN samples compared to free PS. In all the three concentrations tested, the efficiency of quenching by DPN has improved by $\sim 40 \%$ compared to free PS. These results suggest that chemical conjugation of PS to dendrimers did not compromise its ability to generate singlet oxygen.

\section{Binding of Affibody with the DPN}

His-tagged Affibody was purified to $>95 \%$ purity by the methods described earlier. Binding property of Affibody to

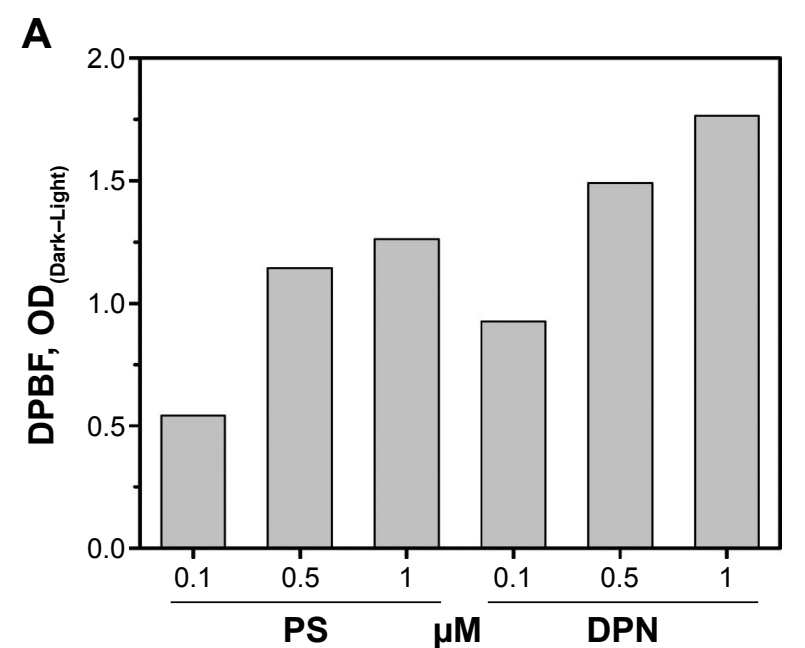

B

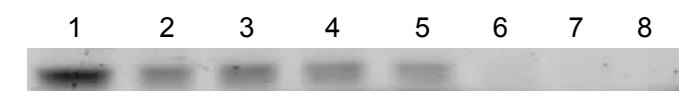

Figure 5 DPBF assay to measure ROS on light exposure.

Notes: (A) Free PS and DPN in DMSO solvent at three different concentrations. (B) Gel binding assay of DPN with Affibody. Approximately $2.5 \mu \mathrm{g}$ of Affibody was incubated with $0.0,0.38,0.75,1.5,3.0,6.0,12.0$ and $15 \mathrm{nmol}$ of PS containing DPN (lanes I-8, respectively).

Abbreviations: DPBF, I,3-diphenylisobenzofuran; ROS, reactive oxygen species; PS, 5, 10, I5,20-tetrakis (4-hydroxyphenyl)-2I H,23H-porphine; PAMAM, poly(amidoamine); DPN, PAMAM-(PS)-Ni-NTA; DMSO, dimethyl sulfoxide; OD, optical density.

the Ni-NTA complex present on DPN was investigated by electrophoresis. With a fixed amount of Affibody $(5 \mu \mathrm{g})$, various amounts of DPN particles $(0.375-15 \mathrm{nmol})$ were incubated for 30 minutes. The unbound sample was separated by centrifugation and visualized by running a SDS-PAGE gel (Figure 5B). Beyond $3 \mathrm{nmol}$ of DPN (based on PS concentration), free Affibody was not observed (Figure 5B). The band intensity of Affibody had progressively decreased with increasing amounts of DPN.

\section{Cell uptake studies by confocal microscopy}

The targetability of the PAMAM dendrimers with the Affibody was tested by evaluating the cellular uptake of DPN and ADPN. Cell uptake studies of free PS, DPN, and ADPN were studied using native fluorescence of PS by incubating $2 \mu \mathrm{M}$ of PS or its equivalent with SK-OV-3 cell lines for 30 minutes. Confocal images of the cells incubated with free PS showed a diffused fluorescence in the entire cell (Figure 6). In cells incubated with DPN and ADPN, the fluorescence was more intense than in free PS exposed cells and also was present as particulate fluorescence, suggesting that DPN and ADPN are localized in vesicles. In addition, ADPN particles show more intracellular fluorescence than DPN particles. 

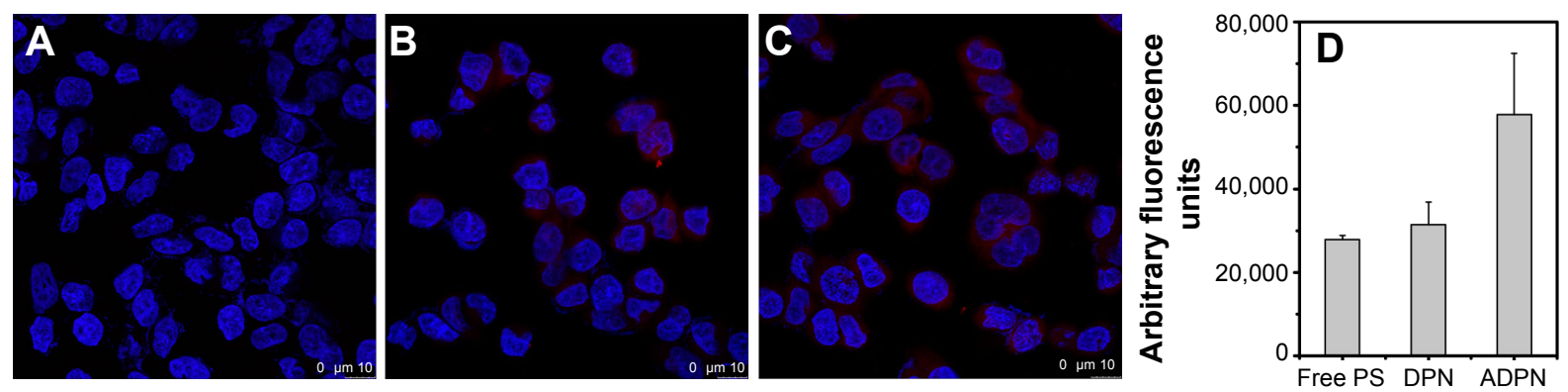

Figure 6 Confocal images of SK-OV-3 cells in the presence of free PS (A), DPN (B), and ADPN (C). Fluorescence intensity from the channel specific to PS in each of the samples is presented (D).

Notes: Nuclei were stained with Hoecsht 33342 dye. Fluorescence of PS was used to image the presence of dendrimers in the cells.

Abbreviations: PAMAM, poly(amidoamine); PS, 5, 10,15,20-tetrakis (4-hydroxyphenyl)-2IH,23H-porphine; DPN, PAMAM-(PS)-Ni-NTA; ADPN, DPN with affinity.

Identical cell uptake experiments were repeated to process the samples for fluorescence-activated cell sorting (FACS) analysis. FACS data confirm the observations made with confocal microscopy, and the data in Figure 7 show that the uptake of PS was efficient in all the cells treated with free PS, DPN, and ADPN. At identical concentrations of PS, dendrimer-bound PS has higher fluorescence inside the cell, and the presence of Affibody on the dendrimer further enhanced its uptake by SK-OV-3 cells.

\section{Light-mediated cell death in the presence of PAMAM dendrimers}

Based on cell uptake studies performed using FACS and confocal imaging, light-mediated cell death was investigated by these particles on HER2+ cells (SK-OV-3) and HER2cells (MCF-7). Abundance of HER2 in SK-OV-3 cells and its absence in MCF-7 cells were earlier demonstrated by Western blot using HER2 (ERBB2) antibodies. ${ }^{34}$ In the PDT studies, each of the treatments was performed in triplicate and in two identical sets. One set was subjected to exposure to light, and another set was protected even from stray light and was treated as a dark control. In initial experiments, the light dose required for PDT and the amount of Affibody required for DPN were optimized. Firstly, we have conducted an experiment with variation of light dosages, and based on these experiments, $20 \mathrm{~J} / \mathrm{cm}^{2}$ was selected as the optimal dose for PDT treatment (data not reported). To optimize Affibody loading on the particles, DPN was incubated with different

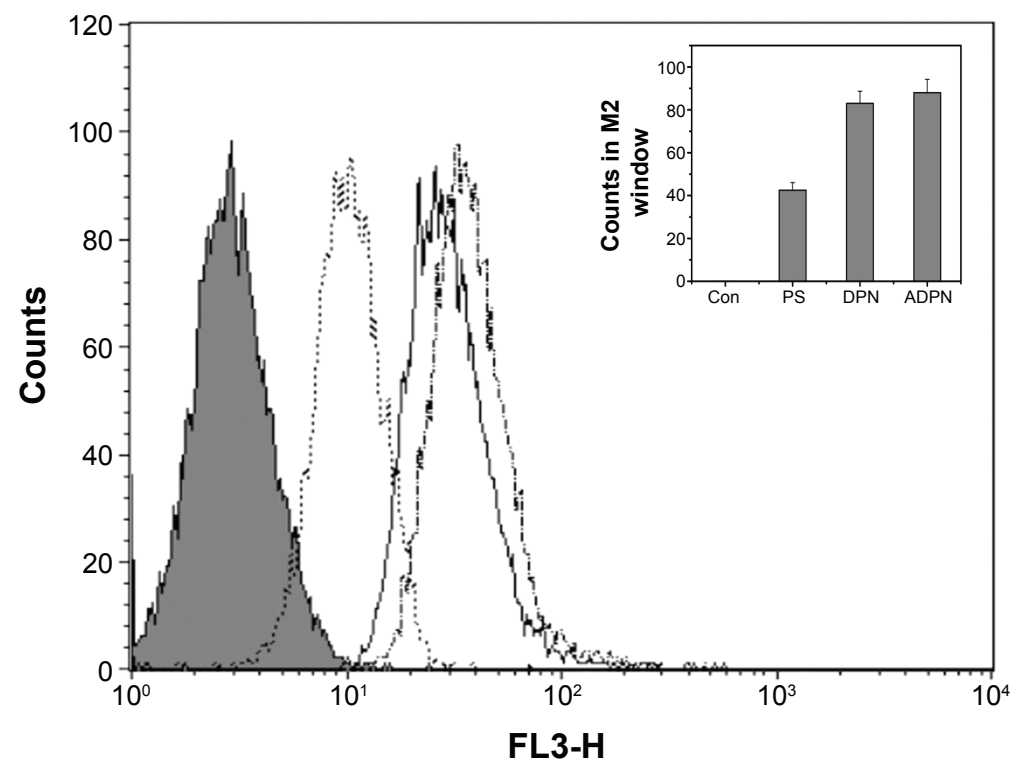

Figure 7 Uptake of free PS and dendrimers by SK-OV-3 cell lines was monitored by FACS.

Notes: Shaded area indicates the background counts due to cells alone. PS was used at $2 \mu \mathrm{M}$ concentration in each of the experiments. Free PS (dotted line), DPN (continuous line), and ADPN (dashed line). (Insert) Fluorescence observed in M2 window was plotted for each treatment.

Abbreviations: PS, 5, I0,15,20-tetrakis (4-hydroxyphenyl)-2IH,23H-porphine; FACS, fluorescence-activated cell sorting; PAMAM, poly(amidoamine); DPN, PAMAM-(PS)-NiNTA; ADPN, DPN with affinity; M2, counts in 10 to 100 in Filter3 (FL3-H) channel; Con, untreated cells. 
concentrations of Affibody and tested on SK-OV-2 cells. Cell death was shown to increase progressively with increasing amounts of Affibody up to $2 \mu \mathrm{g}$ (Figure S2). Based on this study, $2 \mu \mathrm{g}$ Affibody per $500 \mu \mathrm{L}$ of DPN was selected as the most suitable concentration. Cell viability of SK-OV-3 cells pretreated with free PS, DPN, and ADPN was monitored after light exposure. The ratio of cell viability in the presence and absence of light is plotted in Figure 8A.Compared to free PS, DPN has higher efficiency in light-mediated cell death. This effect was further enhanced in the presence of ADPN. The half-maximal inhibitory concentration $\left(\mathrm{IC}_{50}\right)$ of free PS was $0.175 \mu \mathrm{M}$, and this value decreased to $0.1 \mu \mathrm{M}$ with DPN and further to $0.075 \mu \mathrm{M}$ with ADPN. The presence of Affibody on dendrimers showed 2.33 and 1.33 times enhanced PDTmediated cell death compared to free PS and DPN particles, respectively. Similar experiments were performed with MCF7, a cell line that does not overexpress HER2 receptor. $\mathrm{IC}_{50}$ value of PS on MCF7 cells is similar to that of DPN or ADPN (Figure 8B). All the three treatments did not cause cell death in the absence of light exposure. As shown in the Figure S3, these treatments have only marginally reduced $(<15 \%-20 \%)$ the cell viability on their own. This data suggest that the dendrimer preparations, DPN and ADPN, are nontoxic to the cells in the described conditions.

\section{In vivo PDT treatment in SK-OV-3 tumor model in mice}

Improvement of light-mediated cell death by DPN and ADPN over free PS observed on cell lines was further tested in a xenograft tumor animal model. Tumors were initiated

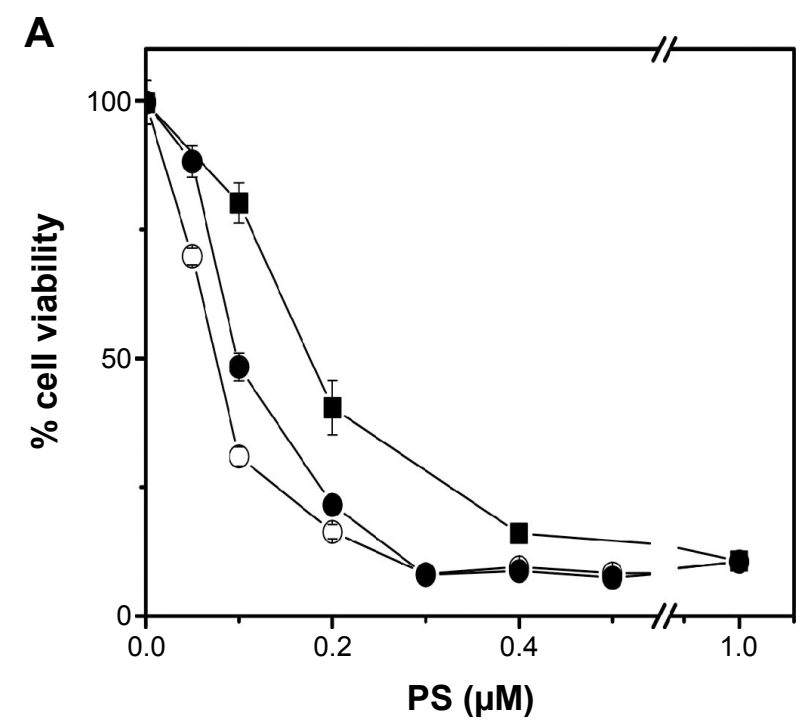

in nude mice by subcutaneous injection of SK-OV-3 cells. At $\sim 100 \mathrm{~mm}^{3}$ of the tumor, the animals were split into two sets of four groups $(n=4)$, and PS formulations were intravenously injected. Except the control that received PBS, all the animals received $3.6 \mathrm{nmol}$ of PS per animal $(100 \mu \mathrm{L})$. ADPN samples were prepared by overnight incubation of $5 \mu \mathrm{g}$ of Affibody with $22 \mathrm{nmol}$ of DPN, and the unbound Affibody was removed by washing. The animals were subjected to PDT, with $120 \mathrm{~J} / \mathrm{cm}^{2}$ energy and exposure time of 10 minutes, 24 hours after the injection. On each subsequent day, the tumor volumes were monitored. Another set of four groups of animals were identically administrated with PS, DPN, and ADPN, but did not undergo PDT. Figure 9A shows data of the tumor volumes of four groups. After 6 days, the tumor volume increased 5.5 times in control animals that did not receive the PS or light. PS-injected animals upon receiving PDT have shown a tumor volume increase of 4.5 times. DPN- and ADPN-injected animals upon light treatment showed only 1.8 and 1.5 times increase in tumor volume compared to day 1 . All the four groups that received PBS, free PS, DPN, and ADPN and did not receive the light treatment also showed tumor volume increase similar to light-treated PBS control group. The experiments were terminated after 8 days due to increase in tumor volumes in control mice. Photographs of representative animals from each group are shown in Figure 9B. The important observation is that DPN and ADPN have shown significant decrease in tumor volume after receiving one dose of light treatment. These studies indicate that PDT treatment slowed the progression of the surface tumor significantly. Based on these studies, it

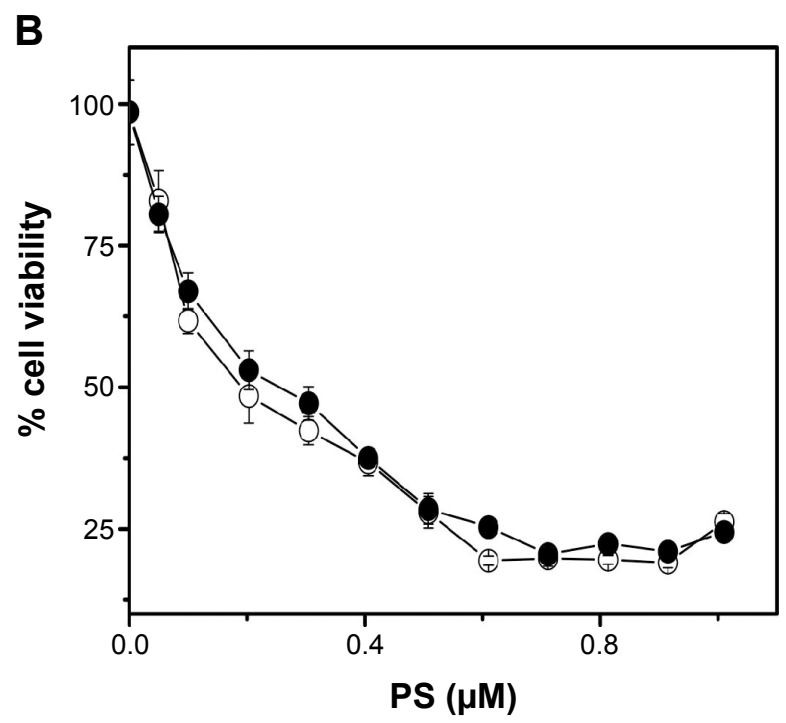

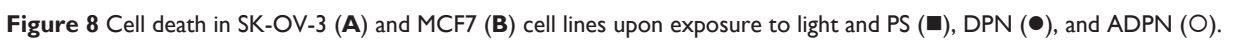
Note: Cell viability was calculated as a ratio of (viability $)_{\text {light }} /(\text { viability })_{\text {dark }}$.

Abbreviations: PAMAM, poly(amidoamine); PS, 5,10,15,20-tetrakis (4-hydroxyphenyl)-2IH,23H-porphine; DPN, PAMAM-(PS)-Ni-NTA; ADPN, DPN with affinity. 
A

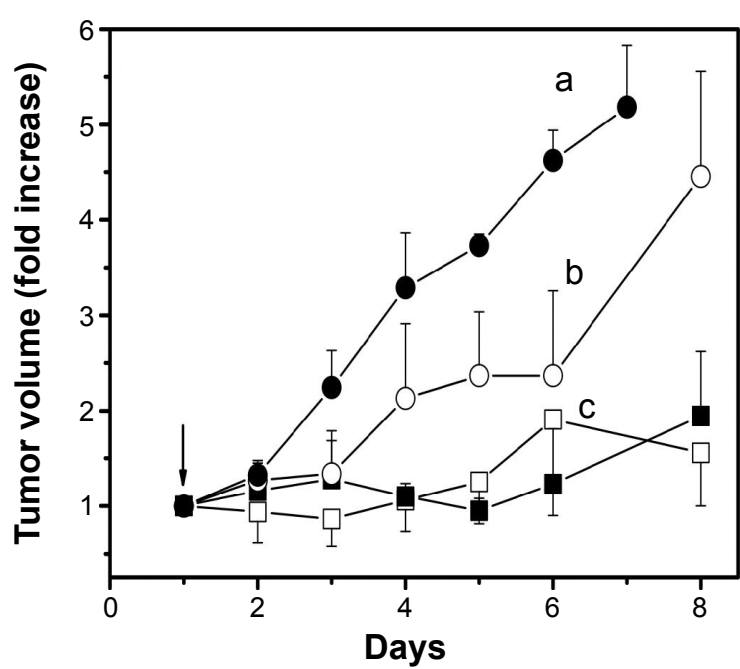

B

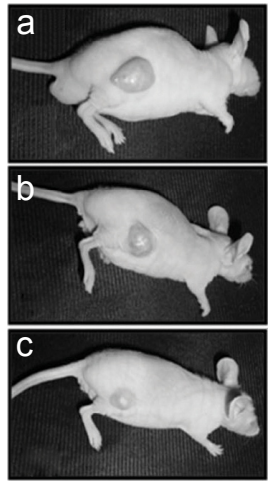

Figure 9 Growth of tumors in nude mice.

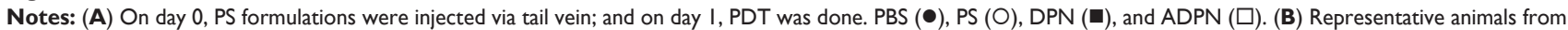
each group were photographed on day 8. PBS (a), PS (b), and DPN/ADPN (c). Animals treated with DPN or ADPN had nearly identical tumor volume. Animals that received PS or DPN or ADPN treatment but were not exposed to light have shown increase in tumor volume similar to PBS treatment.

Abbreviations: PBS, phosphate-buffered saline; PS, 5, 10,15,20-tetrakis (4-hydroxyphenyl)-2IH,23H-porphine; PAMAM, poly(amidoamine); DPN, PAMAM-(PS)-Ni-NTA; ADPN, DPN with affinity.

is possible to completely stall or regress the tumor if multiple doses of PDT are administered. The observed retardation and noninhibition of tumor growth could be attributed to the volume of the tumor $\left(\sim 400-500 \mathrm{~mm}^{3}\right)$, which does not allow proper penetration of the light deep into the tumor. One improvement in the treatment efficacy that could be tested is by initiating the experiments at much smaller tumor volumes and also with multiple exposures to the light.

\section{Discussion}

Targeting drugs to tumor tissue has advantages of lowering the drug doses and significantly decreasing the bystander effects on normal tissue. ${ }^{37,38}$ While free PS was demonstrated to have a benefit ratio of 2-5:1 for tumor to normal tissue, the specific delivery could be significantly enhanced by targeting the PS to the tumor. Low solubility of PS and consequent aggregation also renders the PS to self-quench the triplet-excited state, thus reducing its efficacy. By attaching a PS to nanoparticles, the inherent insolubility problems of PS could be overcome, and also the biodistribution of the PS could be radically altered from that of the free PS to the biodistribution of the particles. ${ }^{39,40}$ By attaching tumorotropic ligands, the biodistribution of PS could be further predisposed toward tumors. In the present study, PAMAM dendrimers were covalently attached to a PS and also to an Affibody (HER2-specific peptide) to render them tumor specific.

The interior of a dendrimer is predominantly hydrophobic and has an ability to make ionic bonds, thus making dendrimers suitable to carry hydrophobic drugs. ${ }^{12}$ Entrapment of hydrophobic drugs in dendrimers has been investigated for its several advantages such as overcoming PS solubility problems, simple formulation procedures, and acceptability to regulatory bodies. However, burst type release kinetics of PS from these formulations and short in vivo half-lives did not result in successful in vivo results. ${ }^{41}$ Covalent association of drugs, such as methotrexate, doxorubicin, etc, with dendrimers has been extensively investigated. ${ }^{25,37}$ Crucial for their efficacy is the optimal release kinetics of the drugs from dendrimers to have therapeutic effect. Stable linkers elicit slow release kinetics. Limitations in drug-release kinetics are overcome by labile linkers, including ester and hydrazine linkers. ${ }^{42}$ With PS-dendrimer conjugates, such limitation is not critical since PS need not interact with biomolecules directly but generates singlet oxygen, which could diffuse to cause cellular damage. Aggregation of PS, a major unproductive consequence, would be absent in PS-dendrimer conjugates. With dendrimers, the stoichiometry of various conjugating moieties per dendrimer could be controlled by fractional derivatization. The G4 PAMAM dendrimer (MW: 14,242.22 Da) used in this study has 64 peripheral amine groups. The extent of conjugation of PS and Ni-NTA groups to dendrimers in this study was derived from the shifts in average mass peaks. By controlled derivatization, 15\% of the carboxylate groups were converted with Ni-NTA groups, resulting in $\sim 10$ NTA moieties per dendrimer. To the NTAdendrimer conjugates, by EDC/DMAP chemistry, 30-32 PS 
molecules were conjugated per dendrimer. Attachment of the PS has not altered the properties of the PS as revealed by UV or fluorescence spectra (Figure 3). The addition of PS apparently did not decrease the ability to generate singlet oxygen as indicated by the DPBF-quenching assay (Figure 5). Intrinsic fluorescence of PS provides an additional mode to monitor its localization within the cell or in the tissues. This aspect is particularly convenient since dendrimers are otherwise spectrally silent.

Targeting of drug-dendrimer conjugates to the tumors was tested earlier. ${ }^{11,14,40,43,44}$ These efforts could be grouped as passive and active targeting. In passive targeting, the physicochemical properties of the conjugates determine the biodistribution. ${ }^{11}$ Size and surface chemistry are the major determinants of biodistribution of the conjugate. As is, synthesized dendrimers are toxic in vitro and in vivo due to their abundant surface charges. Neutralizing the surfaces charges by conjugating drugs or ligands rendered the dendrimers more biocompatible. PEGylation is another functionalization that increased the half-life of dendrimers dramatically, and consequently allows the particles to penetrate into the tumor. ${ }^{24}$ Neovasculature of the tumors is in formative stage, with abnormal structure and wide interendothelial junction. This anomaly in the blood vessels allows particles into the tumor tissue, and the particles tend to remain longer in tumors due to poor lymphatic drainage. The combined effect of entry and lack of exit passively retains nanoparticles in the tumor tissue. This effect known as "enhanced permeability and retention" has been considered as an important reason for accumulation of nanoparticles in the tumors. ${ }^{45,46}$ Active targeting of drugs exploits the altered surface density of several cell receptors on tumor cells and also several extracellular matrix proteins of the endothelial cells. Folic acid and ferritin are widely tested successfully for tumor targeting. ${ }^{47}$ A large number of peptides have been extensively tested for tumor-specific delivery of nanoparticles, prominent among them being RGD and NGR. ${ }^{38,48-50}$ PS-dendrimer conjugates have been tested with 5-ALA, Zn(II)-porphyrins, and pthalocyanines. ${ }^{21}$ PS-dendrimer conjugates with polymeric micelles and other polymeric particles have also been tested. Monoclonal antibody, trastuzumab with infrared (IR) dye700DX was the first antibody and PS conjugate reported that specifically exploited the HER2 expression in cancer cell lines. ${ }^{51}$ EGFR-specific peptide GE-111 peptide and PS (Pc4) were tested successfully against HER2-specific cells using polymeric nanoparticles and PDT. ${ }^{52}$ 5-ALA attached to dendrimers by ester bonds was more efficient on A431 cell lines compared to free 5-ALA. ${ }^{22}$ Third-generation aryl ether dendritic porphyrins, dendrimers of porphyrin monomers, were found to be very efficient in PDT applications. ${ }^{53}$ Several studies used phage display methods to identify efficient tumor-targeting peptides. In addition to peptides, antibodies have been used extensively, especially trastuzumab, for several HER2 overexpressing cell lines. ${ }^{51}$ A detailed study with nanoparticles made with a polymer, camptothecin, and trastuzumab (Herceptin, Genentech, Inc., South San Francisco, CA, USA) showed clear HER2 expression level-dependent cell toxicity effects on HCT116 (HER2 positive) and KB (HER2 negative) cells. ${ }^{54}$ The large size of antibodies poses problems in ligand conjugation and formulation stability. To overcome some of these issues, antibody-like molecules such as Affibody have been tested. Affibody against HER2, used in this study, has been widely investigated for its specificity, targetability, and tumor imaging in several cancers. ${ }^{30,55}$ In our earlier work, we have demonstrated that tumor regression was achieved by Affibody conjugates only on tumors that were generated from EGFR-positive cell line (MDA-MB-453) and not on tumors generated by EGFR-negative cell lines (MDA-MB-231). ${ }^{34}$ In the same study, the inhibitory role of free Affibody in inhibiting gene expression by an Affibody-mediated formulation was also demonstrated. The effect of Affibody conjugation compared to free PS and (PS-dendrimer) DPN is more significant in in vitro cell-based studies. In vivo studies demonstrate a significant improvement in PDT efficacy with DPN and ADPN compared to free PS in tumor regression. However, the improvement by ADPN is marginal compared to dendrimers without Affibody in the experimental period of 8 days. The improved efficacy by DPN and ADPN could be due to combined effects of improved singlet oxygen production (as shown in DPBF assay), improved uptake by cells (as seen by confocal and FACS data), and also enhanced accumulation of the dendrimers in the tumors. Our study protocol involved one injection of PS followed by one light exposure. The observed marginal difference between dendrimers with and without Affibody could be further improved with multiple doses of formulations and longer observation times. PDT effect requires exposure of intratumoral PS to light. Solid tumors of volumes $500 \mathrm{~mm}^{3}$ are large, and unidirectional light exposure to the tumor is going to be of limited value due to poor and partial penetration of the light into the tissue. PS with absorption in longer wavelengths, such as chlorins, would be more effective in improving the PDT effects of PS-dendrimer conjugates. ${ }^{4}$

Uniform size and abundant surface derivatizable groups are attractive features that made dendrimers very popular 
as nanoparticulate scaffolds. Drugs, contrast agents, and synthetic RNA (siRNA) have been successfully delivered using dendrimers. ${ }^{12,13}$ By expressing the Affibody with a His tag, we are able to click in the peptide moiety to Ni-NTA-functionalized dendrimer. This strategy is simple and convenient since any peptide ligand could be expressed with His tag to easily attach to dendrimers. By attaching Affibody and PS to iron oxide NPs, tumor-specific photomediated cell death was demonstrated in vitro and in vivo. ${ }^{56} \mathrm{Ni}$-NTA groups attached to magnetic beads are commercially available to purify His-tagged proteins. We have earlier demonstrated similar affinity purification strategy with Ni-NTA group covalently conjugated to iron oxide particles. ${ }^{57}$ The density of Affibody on a nanoparticle is crucial for its activity. Moderate rather than excessive loading seems to be beneficial for ideal targeting of Affibody. ${ }^{58}$ Our titration experiments with various amounts of Affibody with dendrimer have shown that the cell viability decreases with increasing amounts of Affibody up to $2 \mu \mathrm{g}$. However, it is apparent that similar variations in Affibody to DPN tested in in vitro experiments need to be performed in vivo also to optimize the Affibody loading on the dendrimers.

\section{Conclusion}

Dual functional dendrimers designed in this study are stable and are effective in causing HER2-specific photomediated cell death, both in vitro and in vivo. Significant improvement in PDT efficacy in in vitro experiments was observed with DPN and ADPN compared to free PS. However, while DPN with PDT was very significant in retarding the tumor growth, further improvement with ADPN was not observed in the experimental period. Attachment of PS to the dendrimers neither altered the PS spectra singlet oxygen generating abilities of PS nor the binding properties of the peptide. Simple His-tag-mediated docking of peptides on dendrimers allows reproducible surface densities of the peptide. Uniform size and control over density of surface functionalities make dendrimers a very convenient platform for drug delivery.

\section{Acknowledgments}

The authors thank the financial support received from the CSIR Network grant (BSC0112). NMR and MGA are grateful for the fellowship received from CSIR. The authors also thank the help given by Dr GH Dar.

\section{Disclosure}

The authors report no conflicts of interest in this work.

\section{References}

1. Triesscheijn M, Baas P, Schellens JH, Stewart FA. Photodynamic therapy in oncology. Oncologist. 2006;11:1034-1044.

2. Celli JP, Spring BQ, Rizvi I, et al. Imaging and photodynamic therapy: mechanisms, monitoring, and optimization. Chem Rev. 2010;110: 2795-2838.

3. Kruft BI, Greer A. Photosensitization reactions in vitro and in vivo. Photochem Photobiol. 2011;87:1204-1213.

4. Chen B, Pogue BW, Hoopes PJ, Hasan T. Vascular and cellular targeting for photodynamic therapy. Crit Rev Eukaryot Gene Expr. 2006;16: 279-305.

5. Shirasu N, Nam SO, Kuroki M. Tumor-targeted photodynamic therapy. Anticancer Res. 2013;33:2823-2831.

6. Klajnert B, Rozanek M, Bryszewska M. Dendrimers in photodynamic therapy. Curr Med Chem. 2012;19:4903-4912.

7. Schmitt F, Juillerat-Jeanneret L. Drug targeting strategies for photodynamic therapy. Anticancer Agents Med Chem. 2012;12:500-525.

8. FDA committee has recommended approval of Photofrin ${ }^{\circledR}$ for palliative treatment of late-stage lung cancer. J Clin Laser Med Surgery. 1998; $16: 334$.

9. Bai D, Xia X, Yow CM, Chu ES, Xu C. Hypocrellin B-encapsulated nanoparticle-mediated rev-caspase-3 gene transfection and photodynamic therapy on tumor cells. Eur J Pharmacol. 2011;650: 496-500.

10. Goff BA, Blake J, Bamberg MP, Hasan T. Treatment of ovarian cancer with photodynamic therapy and immunoconjugates in a murine ovarian cancer model. Br J Cancer. 1996;74:1194-1198.

11. Bugaj AM. Targeted photodynamic therapy - a promising strategy of tumor treatment. Photochem Photobiol Sci. 2011;10:1097-1109.

12. Majoros IJ, Williams CR, Baker JR Jr. Current dendrimer applications in cancer diagnosis and therapy. Curr Top Med Chem. 2008;8: 1165-1179.

13. Baker JR Jr. Dendrimer-based nanoparticles for cancer therapy. Hematology Am Soc Hematol Educ Program. 2009;708-719.

14. Liu J, Gray WD, Davis ME, Luo Y. Peptide- and saccharide-conjugated dendrimers for targeted drug delivery: a concise review. Interface Focus. 2012;2:307-324.

15. Chen HT, Neerman MF, Parrish AR, Simanek EE. Cytotoxicity, hemolysis, and acute in vivo toxicity of dendrimers based on melamine, candidate vehicles for drug delivery. J Am Chem Soc. 2004;126: 10044-10048

16. Daftarian P, Kaifer AE, Li W, et al. Peptide-conjugated PAMAM dendrimer as a universal DNA vaccine platform to target antigen-presenting cells. Cancer Res. 2011;71:7452-7462.

17. Kobayashi H, Sato N, Hiraga A, et al. 3D-micro-MR angiography of mice using macromolecular MR contrast agents with polyamidoamine dendrimer core with reference to their pharmacokinetic properties. Magn Reson Med. 2001;45:454-460.

18. Duan X, Sheardown H. Dendrimer crosslinked collagen as a corneal tissue engineering scaffold: mechanical properties and corneal epithelial cell interactions. Biomaterials. 2006;27:4608-4617.

19. Zhang GD, Harada A, Nishiyama N, et al. Polyion complex micelles entrapping cationic dendrimer porphyrin: effective photosensitizer for photodynamic therapy of cancer. $J$ Control Release. 2003;93:141-150.

20. Battah SH, Chee CE, Nakanishi H, Gerscher S, MacRobert AJ, Edwards C. Synthesis and biological studies of 5-aminolevulinic acidcontaining dendrimers for photodynamic therapy. Bioconjug Chem. 2001;12:980-988.

21. Li WS, Aida T. Dendrimer porphyrins and phthalocyanines. Chem Rev. 2009;109:6047-6076.

22. Battah S, Balaratnam S, Casas A, et al. Macromolecular delivery of 5-aminolaevulinic acid for photodynamic therapy using dendrimer conjugates. Mol Cancer Ther. 2007;6:876-885.

23. Cheng Y, Samia C, Meyers JD, Panagopoulos I, Fei B, Burda C. Highly efficient drug delivery with gold nanoparticle vectors for in vivo photodynamic therapy of cancer. J Am Chem Soc. 2008;130: 10643-10647. 
24. Roby A, Erdogan S, Torchilin VP. Enhanced in vivo antitumor efficacy of poorly soluble PDT agent, meso-tetraphenylporphine, in PEG-PE-based tumor-targeted immunomicelles. Cancer Biol Ther. 2007;6:1136-1142.

25. Wang AZ, Langer R, Farokhzad OC. Nanoparticle delivery of cancer drugs. Annu Rev Med. 2012;63:185-198.

26. Jardines L, Weiss M, Fowble B, Greene M. neu(c-erbB-2/HER2) and the epidermal growth factor receptor (EGFR) in breast cancer. Pathobiology. 1993;61:268-282.

27. Arteaga CL, Sliwkowski MX, Osborne CK, PerezEA, Puglisi F, Gianni L. Treatment of HER2-positive breast cancer: current status and future perspectives. Nat Rev Clin Oncol. 2012;9:16-32.

28. Howe LR, Brown PH. Targeting the HER/EGFR/ErbB family to prevent breast cancer. Cancer Prev Res (Phila). 2011;4:1149-1157.

29. Feldwisch J, Tolmachev V. Engineering of affibody molecules for therapy and diagnostics. Methods Mol Biol. 2012;899:103-126.

30. Lofblom J, Feldwisch J, Tolmachev V, Carlsson J, Stahl S, Frejd FY. Affibody molecules: engineered proteins for therapeutic, diagnostic and biotechnological applications. FEBS Lett. 2010;584:2670-2680.

31. Tolmachev V, Orlova A, Nilsson FY, Feldwisch J, Wennborg A, Abrahmsen L. Affibody molecules: potential for in vivo imaging of molecular targets for cancer therapy. Expert Opin Biol Ther. 2007;7: 555-568.

32. Loughran ST, Loughran NB, Ryan BJ, D'Souza BN, Walls D. Modified His-tag fusion vector for enhanced protein purification by immobilized metal affinity chromatography. Anal Biochem. 2006;355:148-150.

33. Wozniak M, Tanfani F, Bertoli E, Zolese G, Antosiewicz J. A new fluorescence method to detect singlet oxygen inside phospholipid model membranes. Biochim. et Biophys Acta. 1991;1082:94-100.

34. Govindarajan S, Sivakumar J, Garimidi P, et al. Targeting human epidermal growth factor receptor 2 by a cell-penetrating peptide-affibody bioconjugate. Biomaterials. 2012;33:2570-2582.

35. Wu B, Kerkeni B, Egami T, et al. Structured water in polyelectrolyte dendrimers: understanding small angle neutron scattering results through atomistic simulation. J Chem Phys. 2012;136:144901.

36. Uehara T, Ishii D, Uemura T, et al. gamma-Glutamyl PAMAM dendrimer as versatile precursor for dendrimer-based targeting devices. Bioconjug Chem. 2010;21:175-181.

37. Zhang L, Gu FX, Chan JM, Wang AZ, Langer RS, Farokhzad OC. Nanoparticles in medicine: therapeutic applications and developments. Clin Pharmacol Ther. 2008;83:761-769.

38. Gajbhiye V, Palanirajan VK, Tekade RK, Jain NK. Dendrimers as therapeutic agents: a systematic review. J Pharm Pharmacol. 2009;61: 989-1003.

39. Huang Z. A review of progress in clinical photodynamic therapy. Technol Cancer Res Treat. 2005;4:283-293.

40. Phillips D. Toward targeted photodynamic therapy. Pure Appl Chem. 2011;83:733-748.

41. Kaminskas LM, McLeod VM, Kelly BD, et al. A comparison of changes to doxorubicin pharmacokinetics, antitumor activity, and toxicity mediated by PEGylated dendrimer and PEGylated liposome drug delivery systems. Nanomedicine. 2012;8:103-111.
42. Lai PS, Lou PJ, Peng CL, et al. Doxorubicin delivery by polyamidoamine dendrimer conjugation and photochemical internalization for cancer therapy. J Control Release. 2007;122:39-46.

43. Yin Z, Liu N, Ma M, Wang L, Hao Y, Zhang X. A novel EGFRtargeted gene delivery system based on complexes self-assembled by EGF, DNA, and activated PAMAM dendrimers. Int J Nanomedicine. 2012;7:4625-4635.

44. Khdair A, Handa H, Mao G, Panyam J. Nanoparticle-mediated combination chemotherapy and photodynamic therapy overcomes tumor drug resistance in vitro. Eur J Pharm Biopharm. 2009;71:214-222.

45. Fang J, Nakamura $H$, Maeda $H$. The EPR effect: unique features of tumor blood vessels for drug delivery, factors involved, and limitations and augmentation of the effect. Adv Drug Deliv Rev. 2011;63:136-151.

46. Fukumura D, Jain RK. Tumor microenvironment abnormalities: causes, consequences, and strategies to normalize. J Cell Biochem. 2007; 101:937-949.

47. Jain RK, Stylianopoulos T. Delivering nanomedicine to solid tumors. Nat Rev Clin Oncol. 2010;7:653-664.

48. Boohaker RJ, Lee MW, Vishnubhotla P, Perez JM, Khaled AR. The use of therapeutic peptides to target and to kill cancer cells. Curr Med Chem. 2012;19:3794-3804.

49. Pearce TR, Shroff K, Kokkoli E. Peptide targeted lipid nanoparticles for anticancer drug delivery. Adv Mater. 2012;24:3803-3822, 3710.

50. MacEwan SR, Chilkoti A. Harnessing the power of cell-penetrating peptides: activatable carriers for targeting systemic delivery of cancer therapeutics and imaging agents. Wiley Interdiscip Rev Nanomed Nanobiotechnol. 2013;5:31-48.

51. Miyano T, Wijagkanalan W, Kawakami S, Yamashita F, Hashida M. Anionic amino acid dendrimer-trastuzumab conjugates for specific internalization in HER2-positive cancer cells. Mol Pharm. 2010;7: 1318-1327.

52. Master AM, Qi Y, Oleinick NL, Gupta AS. EGFR-mediated intracellular delivery of Pc 4 nanoformulation for targeted photodynamic therapy of cancer: in vitro studies. Nanomedicine. 2012;8:655-664.

53. Nishiyama N, Stapert HR, Zhang GD, et al. Light-harvesting ionic dendrimer porphyrins as new photosensitizers for photodynamic therapy. Bioconjug Chem. 2003;14:58-66.

54. Remant BK, Chandrashekaran V, Cheng B, et al. Redox potential ultrasensitive nanoparticle for the targeted delivery of camptothecin to HER2-positive cancer cells. Mol Pharm. 2014;11:1897-1905.

55. Gao J, Chen K, Miao Z, et al. Affibody-based nanoprobes for HER2-expressing cell and tumor imaging. Biomaterials. 2011;32: 2141-2148.

56. Narsireddy A, Vijayashree K, Irudayaraj J, Manorama SV, Rao NM. Targeted in vivo photodynamic therapy with epidermal growth factor receptor-specific peptide linked nanoparticles. Int J Pharm. 2014;471:421-429.

57. Reddy AN, Anjaneyulu K, Basak P, Rao NM, Manorama SV. A simple approach to the design and functionalization of $\mathrm{Fe}_{3} \mathrm{O}_{4}$-Au nanoparticles for biomedical applications. Chempluschem. 2012;77:284-292.

58. Galeazzi S, Hermans TM, Paolino M, et al. Multivalent supramolecular dendrimer-based drugs. Biomacromolecules. 2010;11:182-186. 


\section{Supplementary materials}

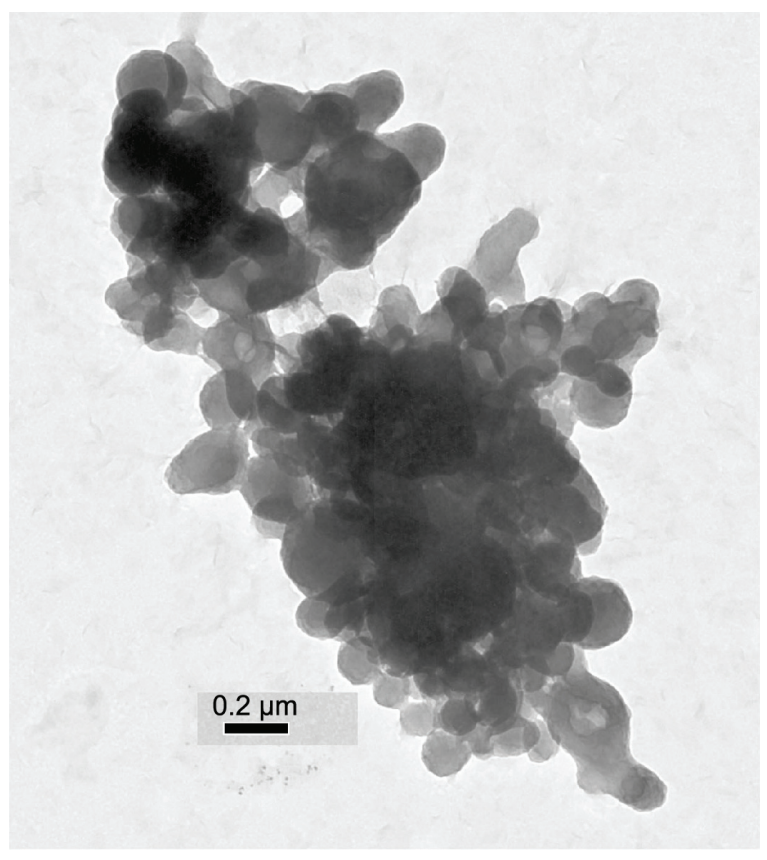

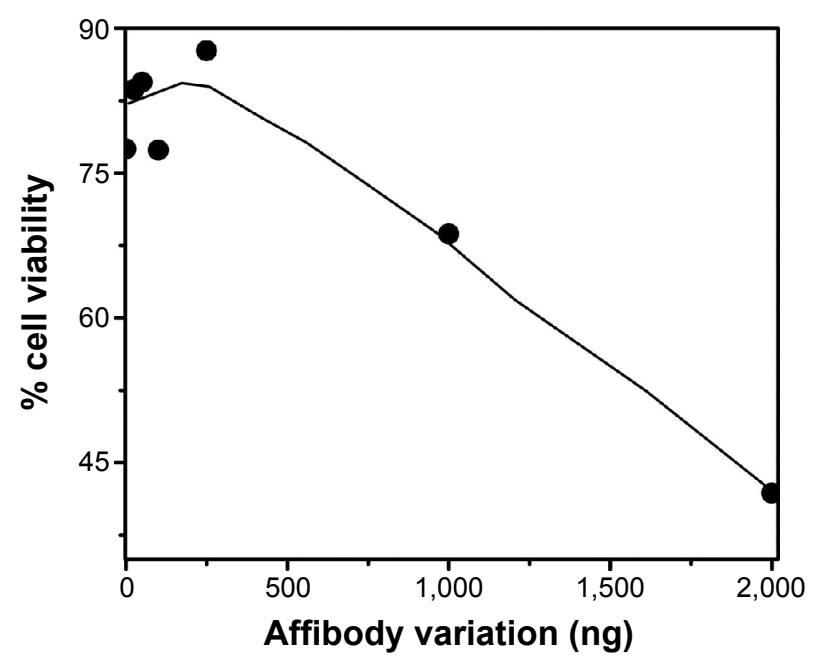

Figure S2 Cell viability of SK-OV-3 cells was tested in the presence of ADPN prepared with various amounts of Affibody.

Abbreviations: PS, 5, I0, I5,20-tetrakis (4-hydroxyphenyl)-2IH,23H-porphine; PAMAM, poly(amidoamine); DPN, PAMAM-(PS)-Ni-NTA; ADPN, DPN with affinity.

Figure SI TEM image of the Affibody-bound dendrimer particle (ADPN).

Abbreviations: TEM, transmission electron microscope; PS, 5, 10,15,20-tetrakis (4-hydroxyphenyl)-2IH,23H-porphine; PAMAM, poly(amidoamine); DPN, PAMAM(PS)-Ni-NTA; ADPN, DPN with affinity.

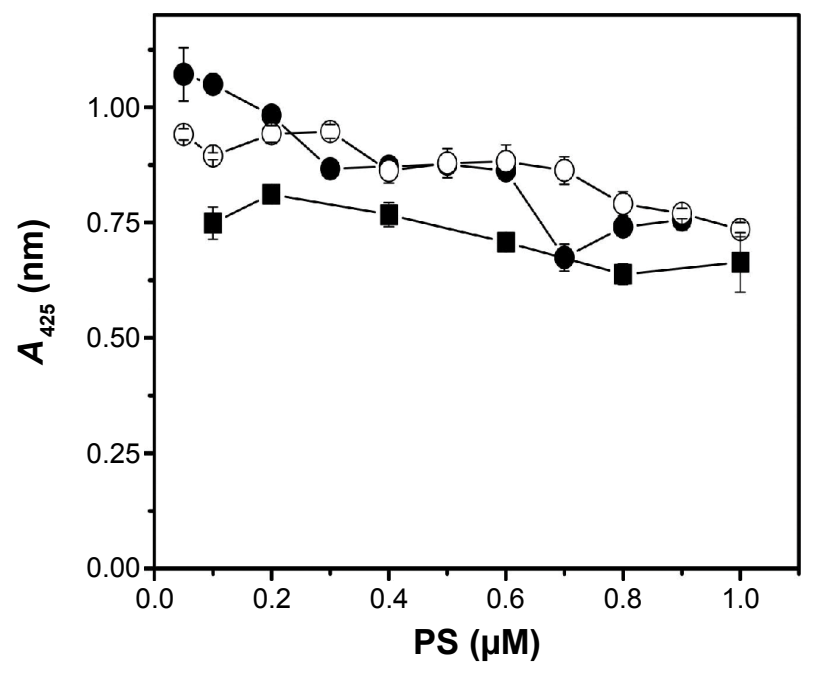

Figure S3 Cell toxicity of PS (dark square), DPN (open circle), and ADPN (dark circle) in SK-OV-3 cells was monitored as cell viability in the presence of PS and in the absence of light treatment.

Note: Absorbance in the absence of PS or light is taken as one.

Abbreviations: PS, 5, 10,15,20-tetrakis (4-hydroxyphenyl)-2IH,23H-porphine; PAMAM, poly(amidoamine); DPN, PAMAM-(PS)-Ni-NTA; ADPN, DPN with affinity.

International Journal of Nanomedicine

\section{Publish your work in this journal}

The International Journal of Nanomedicine is an international, peerreviewed journal focusing on the application of nanotechnology in diagnostics, therapeutics, and drug delivery systems throughout the biomedical field. This journal is indexed on PubMed Central, MedLine, CAS, SciSearch ${ }^{\circledR}$, Current Contents ${ }^{\circledR} /$ Clinical Medicine,

\section{Dovepress}

Journal Citation Reports/Science Edition, EMBase, Scopus and the Elsevier Bibliographic databases. The manuscript management system is completely online and includes a very quick and fair peer-review system, which is all easy to use. Visit http://www.dovepress.com/ testimonials.php to read real quotes from published authors. 